\title{
Enantioselective Analysis of Omeprazole in Pharmaceutical Formulations by Chiral High-Performance Liquid Chromatography and Capillary Electrophoresis
}

\author{
Pierina S. Bonato ${ }^{*, a}$ and Fernanda O. Paias ${ }^{b}$ \\ ${ }^{a}$ Faculdade de Ciências Farmacêuticas de Ribeirão Preto, Universidade de São Paulo, Avenida do Café s/n, \\ 14040-903 Ribeirão Preto - SP, Brazil. \\ ${ }^{b}$ Faculdade de Filosofia, Ciências e Letras de Ribeirão Preto, Universidade de São Paulo, Avenida dos Bandeirantes, \\ 3900, 14040-901 Ribeirão Preto - SP, Brazil.
}

\begin{abstract}
Foram desenvolvidos dois métodos sensíveis e simples baseados em cromatografia líquida de alta eficiência e eletroforese capilar (EC) para a análise enantiosseletiva de omeprazol em formulações. O omeprazol racêmico e (S)-omeprazol foram extraídos de comprimidos disponíveis comercialmente usando metanol: $\mathrm{NaOH} 2,5 \mathrm{~mol} \mathrm{~L}^{-1}(90: 10, \mathrm{v} / \mathrm{v})$. A separação quiral do omeprazol por HPLC foi obtida empregando a coluna CHIRALPAK AD, fase móvel composta por hexano:etanol (40:60, v/v) e detecção em $302 \mathrm{~nm}$. A resolução dos enantiômeros do omeprazol por EC foi obtida empregando $\beta$-ciclodextrina sulfatada (3\% em tampão fosfato, $20 \mathrm{mmol} \mathrm{L}^{-1}, \mathrm{pH} 4.0$ ) e detecção em $202 \mathrm{~nm}$.
\end{abstract}

\begin{abstract}
We developed two sensitive and simple assay procedures based on high- performance liquid chromatography and capillary electrophoresis (CE) for the enantioselective analysis of omeprazole in pharmaceutical formulations. Rac-omeprazole and (S)-omeprazole were extracted from commercially available tablets using methanol: $\mathrm{NaOH} 2.5 \mathrm{~mol} \mathrm{~L}^{-1}(90: 10$, v/v). Chiral HPLC separation of omeprazole was obtained on a CHIRALPAK AD column using hexane:ethanol $(40: 60, \mathrm{v} / \mathrm{v})$ as the mobile phase and detection at $302 \mathrm{~nm}$. The resolution of omeprazole enantiomers by CE was carried out using $3 \%$ sulfated $\beta$-cyclodextrin in $20 \mathrm{mmol} \mathrm{L}^{-1}$ phosphate buffer, $\mathrm{pH} 4.0$ and detection at $202 \mathrm{~nm}$.
\end{abstract}

Keywords: omeprazole, enantiomer, chiral HPLC, chiral CE, pharmaceutical formulation

\section{Introduction}

Twenty-five percent of all drugs used as therapeutic agents are chiral compounds administered to humans as racemates, a mixture of enantiomers which may have very different pharmacological properties. This fact led the Food and Drug Administration (FDA) in the USA and similar regulatory agencies in Europe and Japan to establish guidelines which recommend the production of chiral drugs as single enantiomers. ${ }^{1-3}$ This new trend resulted in an increase in the demand for enantioselective methods for the analysis of drugs in raw materials and pharmaceutical formulations in order to check the enantiomeric purity or enantiomeric excess. In many cases, determination of chiral impurities at concentrations below $0.1 \%$ is required and this places heavy demands on the analytical methods., ${ }^{45}$

High-performance liquid chromatography has been widely used for the enantioselective analysis of chiral

\footnotetext{
* e-mail: psbonato@fcfrp.usp.br
}

drugs, mainly by using chiral stationary phases. Over the last two decades a large number of chiral stationary phases has been described in the literature and some of them are commercially available. Among them, those based on polysaccharides $^{6,7}$ and proteins ${ }^{8}$ have broad applications due to their stability, efficiency and high resolving ability.

High-performance liquid chromatography using chiral stationary phases was the preferred technique for this purpose until the advent of capillary electrophoresis (CE) in the last decade. ${ }^{5,9}$ The main advantages of $\mathrm{CE}$ for the enantioselective analysis of chiral drugs are the extremely high efficiency, instrumentation simplicity, low sample and reagent consumption and speed in method development and analysis. In addition, CE is a complementary technique to high-performance liquid chromatography particularly for the analysis of charged and polar compounds. ${ }^{10}$

In the present study we are reporting two methods based on chiral HPLC and CE for the direct enantioselective analysis of omeprazole in pharmaceutical formulations. Omeprazole (Figure 1), a substituted benzimidazole, is a 
potent inhibitor of gastric acid secretion widely used against acid-related diseases such as peptic ulcer disease and gastroesophageal reflux disease. ${ }^{11}$ Omeprazole contains a tricoordinated sulfur atom in a pyramidal structure and therefore can exist in two different optically active forms, (S)- and (R)-omeprazole. Omeprazole was first approved as a racemic mixture, but the $(\mathrm{S})$ isomer was recently introduced on the market. Both enantiomers have a similar inhibitory effect on acid formation in isolated gastric glands from rabbits, ${ }^{12}$ but (R)-omeprazole is stereoselectivelly hydroxylated by cytochrome P450 CYP2C19 enzime, ${ }^{13}$ resulting in an almost two-fold increase in the plasma concentration for the (S)-isomer than for racemic omeprazole after the administration of equivalent doses. ${ }^{14}$ This leads to a more pronounced inhibitory effect on gastric acid secretion with (S)-omeprazole. ${ }^{15}$

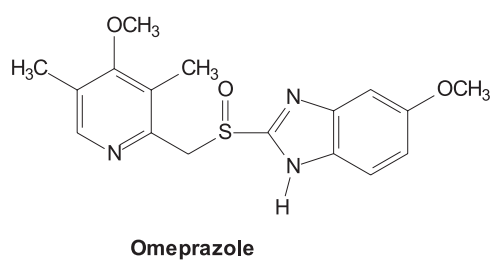

Figure 1. Chemical structure of omeprazole enantiomers.

Several HPLC methods have already been reported for the enantioselective analysis of omeprazole in biological samples or in bulk form. These methods are based on chiral stationary phases, using mainly polysaccharide or protein based columns. ${ }^{16-21}$ As far as chiral CE is concerned, baseline resolution of omeprazole was achieved by Eberle et al. ${ }^{22}$ using bovine serum albumin as chiral selector. Nevertheless, the present work reports for the first time the comparison of two techniques, HPLC and CE for the enantioselective analysis of omeprazole in pharmaceutical formulations.

\section{Experimental}

\section{Instrumentation}

The high-performance liquid chromatography system (Shimadzu, Kyoto, Japan) consisted of an LC-10 AS pump, a Rheodyne model 7125 injector fitted with a $20 \mu \mathrm{L}$ sample loop and an LC-10 A variable UV-Visible detector set at 302 $\mathrm{nm}$. Retention times were obtained with an electronic integrator, Shimadzu model CR-6A interfaced with the detector.

CE experiments were carried out using an Agilent capillary electrophoresis system (Agilent Technologies, Waldbronn, Germany) equipped with an autosampler device, temperature control and a UV-VIS detector operating at $202 \mathrm{~nm}$ and controlled by a ChemStation software on Windows NT. The separation was performed in an uncoated fused-silica capillary (Agilent Technologies) with $60 \mathrm{~cm}$ of length and $50 \mu \mathrm{m}$ of internal diameter. A $0.5 \mathrm{~cm}$ detection window was created by burning off the polyimide coating $53 \mathrm{~cm}$ from the capillary inlet. Samples were hydrodynamically introduced into the capillary over a period of $10 \mathrm{~s}$, at 50 mbar.

\section{Chiral columns}

The chiral columns used for the enantioselective resolution of omeprazole were purchased from Chiral Technologies, Exton, PA, USA (CHIRALCEL OD-H, 150 x $4.6 \mathrm{~mm}$, I.D., $5 \mu \mathrm{m}$ particle size, CHIRALCEL OB-H, $150 \times 4.6 \mathrm{~mm}$, I.D., $5 \mu \mathrm{m}$ particle size, CHIRALCEL OJ-R, $150 \times 4.6 \mathrm{~mm}$, I.D., $5 \mu \mathrm{m}$ particle size, CHIRALPAK AD, $250 \times 4.6 \mathrm{~mm}$, I.D., $10 \mu \mathrm{m}$ particle size and CHIRALPAK AS, 250 x $4.6 \mathrm{~mm}$, I.D., $10 \mu \mathrm{m}$ particle size) and from J.T. Baker, Phillipsburg, NJ, USA (CHIRALAGP, 150 x 4.0 mm, I.D., $5 \mu \mathrm{m}$ particle size).

\section{Chiral selectors for CE}

Sulfated $\beta$-cyclodextrin (degree of substitution, DS, $\sim 7-10$ ) and carboxymethyl $\beta$-cyclodextrin were purchased from Supelco (Bellefonte, PA, USA). $\beta$-cyclodextrin, maltodextrin, and hydroxypropyl $\beta$-cyclodextrin were purchased from Thermo Separation Products Inc. (Eberline Instruments, Santa Fe, New Mexico, USA) and $\beta$-cyclodextrin phosphate was supplied by Cyclolab (Budapest, Hungary).

\section{Chemicals and drug}

The solvents used as mobile phase were HPLC grade, purchased from Merck (Rio de Janeiro, RJ, Brazil) or EM Science (Gibbstown, NJ, USA). All other chemicals were p.a. grade and were provided by Merck (Darmstadt, Germany). Water was purified in a Milli-Q-plus reagent water system (Millipore, São Paulo, SP, Brazil).

The racemic drug omeprazole was kindly supplied by AstraZeneca (São Paulo, Brazil). The stock solution was prepared in methanol: $\mathrm{NaOH} 2.5 \mathrm{~mol} \mathrm{~L}^{-1}$, (90:10, v/v) at the concentration of $1.0 \mathrm{mg} \mathrm{mL}^{-1}$. Working solutions were prepared at the concentration of $50-300 \mu \mathrm{g} \mathrm{mL}^{-1}$ by appropriate dilution.

\section{Chiral separation optimization}

HPLC analysis. The CHIRALCEL OD-H, CHIRALCEL OB-H, CHIRALPAK AD and CHIRALPAK AS columns 
were evaluated under normal phase conditions using hexane/ethanol or hexane/2-propanol as mobile phases. The CHIRALCEL OJ-R column was evaluated under reversed phase conditions, using acetonitrile: $\mathrm{H}_{2} \mathrm{O}$ or na acetonitrile: $\mathrm{NaClO}_{4}$ solution. The CHIRAL AGP column was used with mobile phases consisting of a phosphate buffer solution supplemented with acetonitrile.

Before analysis, the columns were equilibrated by eluting approximately $100 \mathrm{~mL}$ of the mobile phase and the separations were performed in a climatized room $(22 \pm$ $2{ }^{\circ} \mathrm{C}$ ). When the columns were not in use, the mobile phases were replaced with the storage solvent recommended by the column suppliers.

$C E$ analysis. The plain buffer solutions were prepared in water purified with a MilliQ-plus system (Millipore Co., Bedford, USA) at the concentration and $\mathrm{pH}$ required for the analysis, using appropriate amounts of $\mathrm{Na}_{2} \mathrm{PO}_{4}$ and $\mathrm{NaH}_{2} \mathrm{PO}_{4}$, and the chiral selector was further added. The solutions were then sonicated for $5 \mathrm{~min}$ and filtered through $0.45 \mathrm{~mm}$ membranes (Millipore Co., Bedford, USA).

New capillaries were conditioned by rinsing with $\mathrm{NaOH} 1.0 \mathrm{~mol} \mathrm{~L}^{-1}$ for $5 \mathrm{~min}$. Before each analysis the capillary was washed with $\mathrm{NaOH} 0.1 \mathrm{~mol} \mathrm{~L}^{-1}$ ( $2 \mathrm{~min}$ ), water ( $2 \mathrm{~min}$ ) and the running buffer (3 $\mathrm{min})$.

\section{Sample preparation and analysis}

Ten tablets of commercially available samples containing $20 \mathrm{mg}$ of racemic omeprazole or $40 \mathrm{mg}$ of (S)-omeprazole were accurately weighed, ground and homogenized. An amount of $50 \mathrm{mg}$ was transferred to a 50 $\mathrm{mL}$ volumetric flask. After the addition of approximately 40 mL methanol: $\mathrm{NaOH} 2.5 \mathrm{~mol} \mathrm{~L}^{-1}$ (90:10, v/v) solution, the flask was place in an ultrasonicator for 60 minutes and the volume was completed to $50 \mathrm{~mL}$. An aliquot was filtered through $0.45 \mu \mathrm{m}$ membranes (Millipore Co., Bedford, USA). Exactly $25 \mu \mathrm{L}$ of the filtered solution were transferred to a clean tube and the solvent was evaporated under nitrogen flow. The residue was dissolved in $500 \mu \mathrm{L}$ of the mobile phase (hexane:ethanol, 40:60, v/v) and analyzed in the CHIRALPAK AD column, protected by a CN guard column (Merck, Darmstadt, Germany). For the CE analysis, $100 \mu \mathrm{L}$ of the solution was evaporated under nitrogen and the residue was dissolved in $50 \mu \mathrm{L} 2 \mathrm{mmol} \mathrm{L}^{-1}$ phosphate buffer $\mathrm{pH}$ 4.0. An aliquot of this solution was transferred to microvials and analyzed by $\mathrm{CE}$ using $3 \%$ sulfated $\beta$-cyclodextrin in $20 \mathrm{mmol} \mathrm{L}^{-1}$ phosphate, buffer $\mathrm{pH} 4.0$.

\section{Methods of validation}

Calibration curves were prepared by analyzing standard solutions of rac-omeprazole in the concentration range of 50-125 $\mu \mathrm{g} \mathrm{mL}^{-1}$ for each enantiomer. Each standard solution was analyzed in duplicate and plots of peak height versus omeprazole enantiomer concentrations were constructed. Linear regression lines were used for determination of enantiomer concentration in the samples. Linearity of the methods was obtained by analyzing calibration standard in the concentration range of 25-150 $\mu \mathrm{g} \mathrm{mL}^{-1}$, for each enantiomer.

The precision and accuracy of the method were evaluated by determining omeprazole enantiomers in a tablet sample containing $10 \mathrm{mg}$ of each enantiomer. Ten tablets were weighted, powdered and homogenized. For the evaluation of within-day precision and accuracy, aliquots of $50 \mathrm{mg}(\mathrm{n}=10)$ were analyzed on the same day according to the procedure previously described. Between day experiments were carried out by analyzing aliquots of this sample for 5 days.

The detection limit and quantitation limit were defined as $3(\sigma / \mathrm{S})$ and $10(\sigma / \mathrm{S})$ where s is the standard deviation of the response for a replicate analyses of a sample $(n=10)$ and $\mathrm{S}$ is the slope of the calibration curve. ${ }^{23}$

\section{Results and Discussion}

Polysaccharide based stationary phases together with the chemically bound protein phases have proved to be the most useful stationary phases for the resolution of chiral drugs by high-performance liquid chromatography.

In the present study, these columns were evaluated for the resolution of omeprazole and some selected separation and chromatographic conditions are shown in Figure 2. Among the chiral columns evaluated, only CHIRALCEL OJ-R did not show complete resolution of omeprazole. The CHIRALPAK AD column was selected for development of the method due to its stability and high resolving ability.

Among the several chiral selectors reported in the literature for $\mathrm{CE}$ enantioselective analysis of drugs, cyclodextrins (CD) and their derivatives are the most widely used due to their high enantioselectivity. ${ }^{24}$ The derivatization of the hydroxyl groups of CD with various functional groups improved the solubility and increased the specific interactions between the CD and enantiomers. The resolution of neutral compounds is possible by using charged CD derivatives. One of the most successful charged $\mathrm{CD}$ is sulfated $\beta$-CD, whose mobility is opposite to the electroosmotic flow showing high strong resolving power even at very low concentrations. ${ }^{25}$ Sulfated $\beta$-CD has been successfully used by our group for the enantiomeric separation of a series of pharmaceutical compounds. ${ }^{26-29}$ 

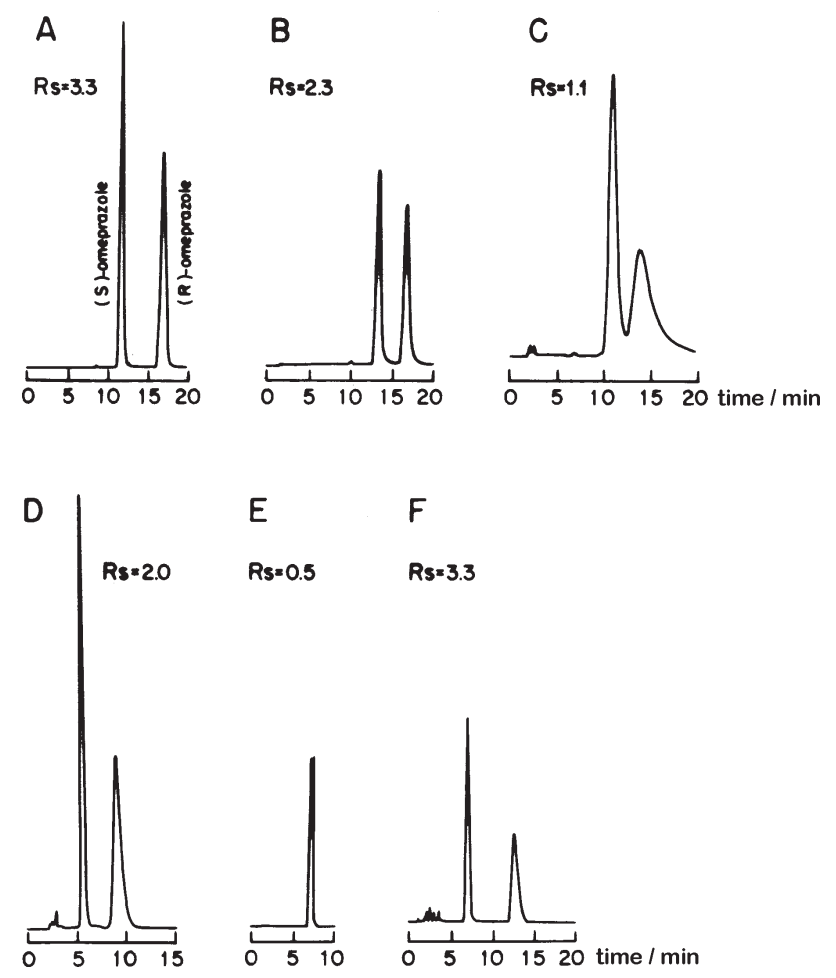

Figure 2. Chiral resolution of omeprazole using chiral stationary phases. (a) CHIRALPAK AD/hexane:ethanol (40:60, v/v), 0.7

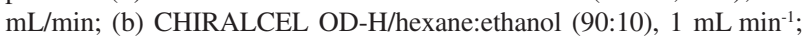
(c) CHIRALCEL OB-H/hexane:ethanol (93:7, v/v), $1 \mathrm{~mL} \mathrm{~min}^{-1}$; (d) CHIRALPAK AS/hexane:ethanol $(80: 20, \mathrm{v} / \mathrm{v}), 1.5 \mathrm{~mL} \mathrm{~min}^{-1}$; (e) CHIRALCEL OJ-R/ $\mathrm{H}_{2} \mathrm{O}$ :acetonitrile $(70: 30, \mathrm{v} / \mathrm{v}), 0.5 \mathrm{~mL} \mathrm{~min}^{-1}$; (f) CHIRAL AGP/phosphate buffer $20 \mathrm{mmol} \mathrm{L}^{-1}$, $\mathrm{pH}$ 4.7:acetonitrile $(93: 7, \mathrm{v} / \mathrm{v}), 1 \mathrm{~mL} \mathrm{~min}^{-1}$; detection at $302 \mathrm{~nm}$.

$\beta$-CD and some of its neutral and charged derivatives were evaluated for the resolution of omeprazole enantiomers. The complete resolution of omeprazole was only obtained using sulfated $\beta$-CD (Figure 3).

The elution order established by the injection of the pure (S)-enantiomer was the same for both methods, i.e,

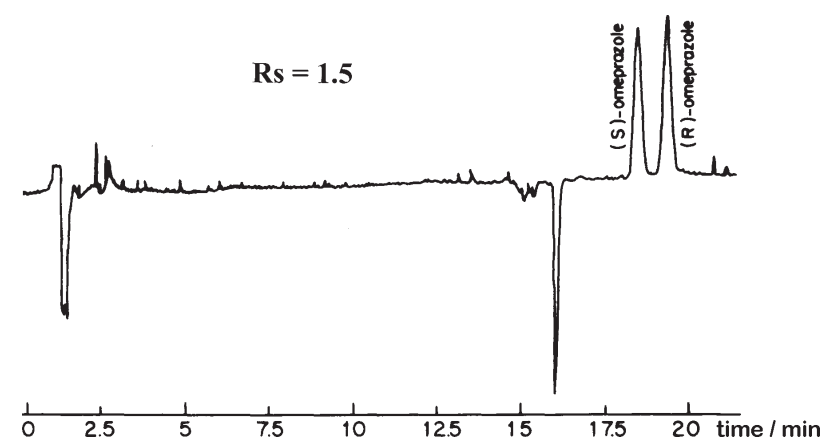

Figure 3. Electropherogram for the chiral separation of omeprazole using sulfated $\beta$-CD derivative. Conditions: $3 \%$ sulfated $\beta$-cyclodextrin in $20 \mathrm{mmol} \mathrm{L}^{-1}$ phosphate buffer, $\mathrm{pH} \mathrm{4}$; applied voltage: $20 \mathrm{kV}$; temperature: $20{ }^{\circ} \mathrm{C}$; hydrodynamic injection (50 mbar, 10 seconds); UV detection at $202 \mathrm{~nm}$.
(S)-omeprazole eluting first. The resolution of the HPLC method is higher than that of the CE method $(3.3 \times 1.5)$ which represents an advantage for the HPLC method.

Sample preparation was carried out by dissolving omeprazole from the tablets using a methanol: $\mathrm{NaOH}$ $2.5 \mathrm{~mol} \mathrm{~L}^{-1}(90: 10, \mathrm{v} / \mathrm{v})$ solution in order to avoid drug
A

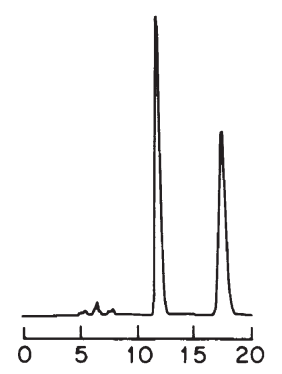

B

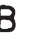

Figure 4. Chiral resolution of omeprazole by HPLC. (a) commercial tablet of rac-omeprazole; (b) commercial tablet of (S)-omeprazole. Mobile phase: hexane:ethanol $(40: 60, \mathrm{v} / \mathrm{v})$ at a flow rate of $0.7 \mathrm{~mL}$ $\min ^{-1}$; detection at $302 \mathrm{~nm}$. Column protected by a CN guard column.

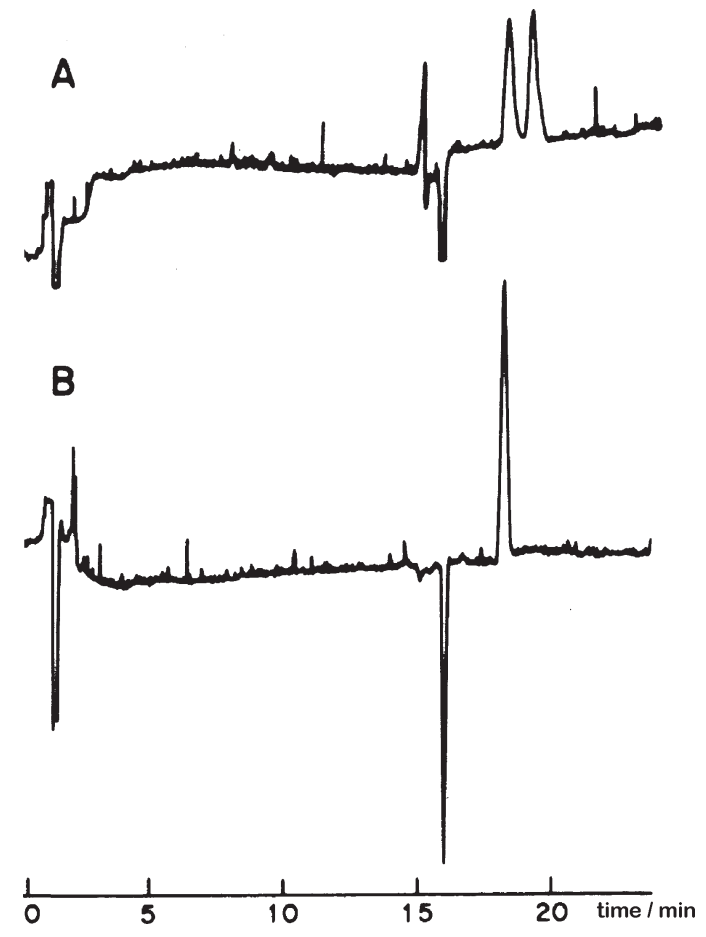

Figure 5. Enantiomeric separation of omeprazole by capillary electrophoresis. (a) commercial tablet of rac-omeprazole; (b) commercial tablet of (S)-omeprazole. Conditions: $3 \%$ sulfated $\beta$-cyclodextrin in $20 \mathrm{mmol} \mathrm{L}^{-1}$ phosphate buffer, $\mathrm{pH} \mathrm{4}$; applied voltage: $20 \mathrm{kV}$; temperature: $20{ }^{\circ} \mathrm{C}$; hydrodynamic injection (50 mbar, 10 seconds); UV detection at $202 \mathrm{~nm}$. 
Table 1. Validation parameters for the methods

\begin{tabular}{|c|c|c|c|c|}
\hline & \multicolumn{2}{|c|}{$\mathrm{CE}$} & \multicolumn{2}{|c|}{ HPLC } \\
\hline & $(\mathrm{S})$-omeprazole & (R)-omeprazole & (S)-omeprazole & (R)-omeprazole \\
\hline \multicolumn{5}{|l|}{ Within-day precision } \\
\hline Amount in one tablet ${ }^{\mathrm{a}}(\mathrm{mg})$ & 9.8 & 9.8 & 9.9 & 10.1 \\
\hline $\mathrm{n}$ & 10 & 10 & 10 & 10 \\
\hline $\mathrm{CV}(\%)$ & 1.8 & 1.8 & 1.7 & 1.7 \\
\hline \multicolumn{5}{|l|}{ Between-day precision } \\
\hline Amount in one tablet ${ }^{\mathrm{a}}(\mathrm{mg})$ & 9.9 & 9.9 & 10.0 & 9.8 \\
\hline $\mathrm{n}$ & 5 & 5 & 5 & 5 \\
\hline $\mathrm{CV}(\%)$ & 1.9 & 1.7 & 1.9 & 1.8 \\
\hline \multicolumn{5}{|l|}{ Accuracy } \\
\hline Within-day (\%) & -2.0 & -2.0 & -1.0 & 1.0 \\
\hline Between-day (\%) & -1.0 & -1.0 & 0 & -2.0 \\
\hline Detection limit ${ }^{\mathrm{b}}\left(\mathrm{ng} \mathrm{mL}^{-1}\right)$ & 617 & 1317 & 2.8 & 6.1 \\
\hline Quantitation limit $^{\mathrm{b}}\left(\mathrm{ng} \mathrm{mL}^{-1}\right)$ & 2057 & 4339 & 9.4 & 20.4 \\
\hline
\end{tabular}

a each tablet contains $20 \mathrm{mg}$ of rac-omeprazole; ${ }^{\mathrm{b}}$ concentration of the solution injected. $\mathrm{n}$, number of determinations; CV, coefficient of variation.

decomposition. ${ }^{16,19}$ This solution was also used for the preparation of the standard solutions which were stable for at least a month when stored at $-20{ }^{\circ} \mathrm{C}$, in the dark.

Figure 4 and 5 respectively show the chromatograms and eletropherograms obtained for the analysis of commercially available samples of rac-omeprazole and (S)-omeprazole.

Calibration curves were linear over the concentration range of 25 to $150 \mu \mathrm{g} \mathrm{mL}^{-1}$ for both methods, with correlation coefficients better than 0.99 . The precision and accuracy experiments were carried out using a commercially available sample of rac-omeprazole and the results are shown in Table 1. Both methods show accuracy and precision of the order of a few percent. Student's t-test and F-test show that accuracy and precision, respectively, are not statistically different (95\% confidence level).

Detection limits and quantitation limits also reported on Table 1 show that the HPLC method is more sensitive. This is not a problem for drug assay since the amount of sample is not a limiting factor.

\section{Conclusion}

The present results confirm that the proposed chiral HPLC and CE methods were well suited for the enantioselective analysis of omeprazole in pharmaceutical formulations. Chiral CE is more versatile and less expensive than HPLC using chiral columns, since several expensive columns are required to cover a reasonably wide application range and column lifetime tends to be relatively short. In addition, chiral HPLC requires a large volume of organic solvents. On the other hand, the HPLC method is more sensitive and resulted in a better resolution of omeprazole enantiomers.

\section{References}

1. De Camp, W. H.; Chirality 1989, 1, 2.

2. Jamali, F.; Mehvar, R.; Pasutto, F. M.; J. Pharm. Sci. 1989, 78, 695.

3. Stinson, S. C.; Chem. Eng. News 2000, 78, 55.

4. Blomberg, L. G.; Wan, H.; Electrophoresis 2000, 21, 1940.

5. Maier, N. M.; Franco, P.; Lindner, W.; J. Chromatogr. A 2001, 906, 3 .

6. Okamoto, Y.; Kaida, Y.; J. Chromatogr. A 1994, 666, 403.

7. Yashima, E.; Okamoto, Y.; Bull. Chem. Soc. Jpn 1995, 68, 3289.

8. Allenmark, S. G.; Andersson, S.; J. Chromatogr. A 1994, 666, 167.

9. Nishi, H.; Electrophoresis 1999, 20, 3237.

10. Blaschke, G.; Chankvetadze, B.; J. Chromatogr. A 2000, 875, 3.

11. Lindberg, P.; Nordberg, P.; Alminger, T.; Brändström, A.; Wallmark, B.; J. Med. Chem. 1986, 29, 1327.

12. Erlandsson, P.; Isaksson, R.; Lorentzon, P.; Lindberg, P.; J. Chromatogr. B 1990, 532, 305.

13. Tybring, G.; Böttiger, Y.; Widén, J.; Bertilsson, L.; Clin. Pharmacol. Ther. 1997, 62, 129.

14. Andersson, T.; Rohss, K.; Hassan-Alin, M.; Bredberg, E.; Wayne, P. A.; Gastroenterology 2002, 118, suppl.2, 5550.

15. Richter, J. E.; Kahrilas, P. J.; Johanson, J.; Maton, P.; Breiter, J. R.; Hwang, C.; Marino, V.; Hamelin, B.; Levine, J. G.; Am. J. Gastroenterol. 2001, 96, 656.

16. Stenhoff, H.; Blomqvist, A.; Lagerström, P. O.; J. Chromatogr. B 1999, 734, 191.

17. Balmer, K.; Persson, B. A.; Lagerström, P. O.; J. Chromatogr. A 1994, 660, 269.

18. Cairns, A. M.; Chiou, R. H. Y.; Rogers, J. D.; Demetriades, J. L.; J. Chromatogr. B 1995, 666, 323. 
19. Tanaka, M.; Yamazaki, H.; Hakusui, H.; Chirality 1995, 7, 612.

20. Karlsson, A.; Hermansson, S.; Chromatographia 1997, 44, 10.

21. Cass, Q. B.; Degani, A. L. G.; Cassiano, N.; J. Liq. Chromatogr. Rel. Technol. 2000, 23, 1029.

22. Eberle, D.; Hummel, R. P.; Kuhn, R.; J. Chromatogr. A 1997, $759,185$.

23. http://www.fda.gov/cder/guidance/1320fnl.pdf; accessed in january 2002.

24. Schneiderman, E.; Stalcup, A. M.; J. Chromatogr. B 2000 , $745,83$.

25. De Boer, T.; De Zeeuw, R. A.; De Jong, G. J.; Ensing, K.; Electrophoresis 2000, 21, 3220.
26. Paias, F. O.; Lanchote, V. L.; Takayanagui, O. M.; Bonato, P. S.; Electrophoresis 2001, 22, 3263.

27. Bonato, P. S.; Jabor, V. A P.; Paias, F. O.; Lanchote, V. L.; J. Liq. Chromatogr. Rel. Technol. 2001, 24, 1115.

28. Jabor, V. A. P.; Bonato, P. S.; Electrophoresis 2001, 22, 1399.

29. Jabor, V. A . P.; Lanchote, V. L.; Bonato, P. S.; Electrophoresis 2001, 22, 1406.

Received: September 16, 2002 Published on the web: April 8, 2004

FAPESP helped in meeting the publication costs of this article. 